\title{
O NARRATÁRIO COMO CONFIDENTE: METAFICÇÃO E QUEBRA DA QUARTA PAREDE EM HOUSE OF CARDS
}

\section{NARRATEE LIKE BEST FRIEND: METAFICTION AND BROKEN FOURTH WALL IN HOUSE OF CARDS}

\author{
Fabiana Piccinin \\ Doutora em Comunicação Social pela Pontifícia Universidade Católica do Rio Grande do Sul \\ Professora e Pesquisadora do Programa de Mestrado em Letras da Universidade de Santa Cruz do Sul \\ E-mail: fabi@unisc.br
}

Gabriel Steindorff

Mestre em Letras pela Universidade Católica do Rio Grande do Sul Professor e Pesquisador da Universidade Católica do Rio Grande do Sul

E-mail: gabriels@unisc.br

\section{RESUMO}

A partir da teoria da narrativa, o artigo discute a mudança de relação entre o narrador intradiegético e seu espectador ideal, o narratário. Propõe esta reflexão por meio da reflexão sobre a quebra "quarta parede" que, cria um novo nível narrativo mediante o rompimento com um esquema clássico de narrativa oriundo do teatro e adaptado para o cinema e a Tv. Neste nível, o narrador intradiegético entrega informações exclusivas ao narratário, entendido como o espectador ideal, oportunizando a duplicação da ficção mediante a criação de níveis narrativos metaficcionais e, por extensão, reforçando o sentido de cumplicidade com a audiência. Do ponto de vista empírico, a análise da quebra da quarta parede é feita a partir do estudo da minissérie House of Cards, marcada pela estrutura narrativa em que o narrador dialoga em um nível com os personagens da diegese e em outro nível distinto com o narratário, lhe confidenciando informações exclusivas.

Palavras-chave: Quarta Parede. Metaficção. House of Cards. Níveis Diegéticos.

\begin{abstract}
Applying the narrative theory, the essay focuses on the change in the relation between the intradiegetic narrator and his ideal spectator, the narratee. This reflection is proposed through the idea of a broken fourth wall, which creates a new narrative level through the rupture with a classical narrative framework originally from theater and adapted to cinema and television. In this level, the intradiegesis narrator delivers exclusive information to the narratee, here
\end{abstract}


understood as the ideal spectator, providing a duplication of the fiction by the making of metafictional narrative levels and, further, strengthening the meaning of the complicity with the public. Through the empirical view, the analysis of the broken fourth wall is done through the study of the miniseries House of Cards, characterized by the narrative structure in which the narrator dialogs, in a level with diegetic characters and, in another level, with the narratee, telling him exclusive information.

Key-words: Forth Wall. Metafiction. House of Cards. Diegetic Levels.

\section{A HERANÇA DO TEATRO}

A “quarta parede" apresenta-se como uma questão central na narrativas articuladas a partir da representação em som e imagem na medida em que resulta em implicações fundamentais na estruturação da história, desde o teatro, sendo seguida depois pelo cinema e, mais tarde, pela televisão. Originalmente o conceito consistia, segundo Xavier (2003), em os atores ignorarem o público e representarem como se uma suposta realidade se apresentasse diante da platéia. Desta forma, o espectador teria a impressão de que a peça teatral seria uma realidade paralela, um extra-mundo, no qual, existiriam três paredes sólidas e opacas que constituiriam as laterais e o fundo do cenário, e uma quarta parede "invisível", entre o público e os atores, por onde se observaria a ação. Por conta disso, esta parede "invisível", deveria ser ignorada pelos personagens, num processo em que fingem que seja tão sólida e opaca quanto as outras três.

\footnotetext{
No século XVII, o teatro assumiu com maior rigor a "quarta parede" e fez a mise-enscène se produzir como uma forma de tableu que, tal como uma tela composta com cuidado pelo pintor define um espaço contido em si mesmo, sugere um mundo autônomo de represemtação, totalmente separado da plateia. Como queria Diderot, a "quarta parede" significa uma cena autobastante, absorvida em si mesma, contida em seu próprio mundo, ignorando o olhar externo a ela dirigido, evitando qualquer sinal de interesse pelo espectador, pois os atores estão "em outro mundo". (XAVIER, 2003, p.17)
}

Metz (1985) traz esta discussão para o âmbito do cinema e compara esta separação de dois mundos, como se os atores estivessem em um aquário, e não diante de uma parede invisível. Para o autor, para que haja esta dualidade é necessário que o ator finja que não está sendo visto, fingindo também que seu personagem existe para além da narrativa. Assim, fingiria manter suas ocupações rotineiras e sua existência seria anterior à história narrada. $\mathrm{O}$ autor explica que o mais provável, ao ignorar que uma das paredes trata-se de retângulo de vidro, "é que vive numa espécie de aquário um pouco mais avaro dos seus dias que os aquários verdadeiros (esta retenção faz ela mesma parte do jogo escópico)." [grifos do autor] (METZ, 1985, p.122) 
Em razão disso, segundo Xavier (2003), a ficção fica aprisionada no seu mundo paralelo e protegida da realidade. $\mathrm{O}$ autor esclarece que o poder de aprisionamento do cinema é maior que o do teatro, "pois o espaço imaginário se projeta na pura superfície (a luz da tela); não há atores no espaço da sala, o que auxilia na produção do efeito de autonomia da ficção.” (XAVIER, 2003, p.18)

Esse aprisionamento da ficção que promove a criação de um mundo paralelo para a representação cênica é em muito tributária ao efeito de real que o teatro, e posteriormente o cinema, pretendiam criar. Uma realidade em que o espectador crê, por alguns momentos, fazer parte. No caso do cinema, Bernardet (2001) compara a impressão de realidade da tela grande com a impressão de realidade que o indivíduo experimenta ao sonhar e que só apercebe-se que está sonhando quando acorda, já que enquanto ainda está dormindo, o indivíduo acredita que está vivendo a realidade.

O cinema dá a impressão de que é a própria vida que vemos na tela, brigas verdadeiras, amores verdadeiros. Mesmo quando se trata de algo que sabemos não ser verdade, como o Pica-pau Amarelo ou O Mágico de Oz, ou um filme de ficção científica como 2001 ou Contatos Imediatos do Terceiro Grau, a imagem cinematográfica permite-nos assistir a essas fantasias como se fossem verdadeiras; ela confere realidade a essas fantasias. [grifos do autor] (BERNARDET, 2001, p.12)

Por outras palavras, é dizer que, quando está no cinema, o espectador "esquece" que está sentado numa poltrona e tem a impressão que está vivenciando as situações mostradas no filme. Metz (1985) explica que a eficácia do discurso cinematográfico se dá pela habilidade deste em esconder as marcas de sua enunciação. Ou como diz Bernardet (2001), a impressão de realidade só se mantém se o aparato do cinematográfico ficar oculto.

Balázs (2003) também aponta para o efeito de realidade promovido através da identificação do espectador com os personagens do filme, quando este é "carregado" - de forma imaginária - pela câmera para dentro do filme, e assim, não precisa ser informado dos sentimentos do personagem posto que vê o que o personagem vê, e assim é induzido a sentir o que o personagem sente.

Embora nos encontremos sentados nas poltronas pelas quais pagamos, não é de lá que vemos Romeu e Julieta. Nós olhamos para cima, para o balcão de Julieta com os olhos de Romeu e, para baixo, para Romeu, com os olhos de Julieta. Nosso olho, e com ele nossa consciência, identifica-se com os personagens no filme; olhamos para o mundo com os olhos deles e, por isso, não temos nenhum ângulo de visão próprio. Andamos pelo meio de multidões, galopamos, voamos ou caímos com o herói, se um personagem olha o outro nos olhos, ele olha da tela pra nós. Nossos olhos estão na câmera e tornamse idênticos aos olhares dos personagens. Os personagens veem com os nossos olhos. É neste fato que consiste o ato psicológico de identificação. (BALÁZS, 2003, p.85) 
Em razão disso, o procedimento de identificação com o personagem gera uma espécie de internalização da origem da informação. O espectador, segundo Browne (2005), tem a sensação de que quem conta a história são os personagens e não todo o aparato audiovisual em conjunto. E crê que o efeito de real proporcionado pelo cinema seja, portanto, tributário à manutenção da quarta parede, porque é esta que permite o jogo da simulação a partir do qual se frui a "história real", valendo-se da suspensão da descrença necessária para tal.

\section{NÍVEIS DIEGÉTICOS E METAFICÇÃO}

Para explicar o rompimento da quarta parede como contrato narrativo, Hutcheon (1984) vale-se do conceito de metaficção, que segundo a autora, pode ser entendida, neste caso, como metaficção do tipo narcisista porque é basicamente uma ficção que tem em si mesma seu referente, que fala sobre si mesma e se reflete em si mesma. Neste sentido, a autora faz relação com o mito grego, em que Narciso passava seus dias diante do lago vendo seu próprio reflexo e, assim, teria se apaixonado por si mesmo.

Do ponto de vista da narrativa, portanto, o termo narcisista é atribuído às histórias marcadas pela introspecção, introversão e autorreferência. É dizer que, nessa perspectiva de metaficção, o foco de atenção do romance se desloca para seus processos internos, fazendo referência ao imaginário ou às condições e situações psicológicas dos personagens. Assim, há possibilidade, por exemplo, de conceber romances que tratam de um leitor de romances, ou de filmes que tratam de personagens de cinema de modo a evidenciar que o foco está na própria obra, refletindo-se e se autorreferenciando.

Já quanto ao papel do leitor ou da audiência, este altera-se fundamentalente posto que não se encontra mais numa posição confortável, puramente de espectador da narrativa. A partir da metaficção, sua participação é exigida de maneira mais explícita e convocatória para que dê conta das funções de controle, organização e interpretação deste texto, passando a usufruir de informações exclusivas na relação com a diegese. Deste modo, ao contrário do que a ficção realista propõe originalmente, os acontecimentos da história são direcionados ao leitor ideal como segunda pessoa, como uma entidade a quem o narrador se dirige diretamente. Ou como o narratário na obra metaficcional.

Para Hutcheon (1984) há diferença das sensações proporcionadas ao leitor/espectador da metaficção em relação ao romance realista. Para a autora, a narrativa realista traz a sensação de completude, ou seja, a sensação de que só a arte poderia completar o ser humano e dar sentido 
à sua existência. Já na metaficção, a ambiguidade e a inexistência de um final fechado, permitindo a interpretação ativa do leitor, sugeririam insegurança ou um conflito entre a necessidade de ordem e a situação do homem no mundo real e caótico, complexificando esta relação.

Assim, a metaficção se constituiria como uma "ficção verdadeira" e não dissimulada ao contrário da ficção realista, já que esta última se disfarça de uma realidade possível. Para compreendê-la, neste sentido, a autora propõe uma mudança no paradigma de interpretação da história, como por exemplo, a concepção de cenários que seriam pouco verossímeis à ficção realista. E o próprio genero metaficcional se mostraria exposto ao leitor, transgredindo a característica realista de ocultar sua estrutura ficcional.

Hutcheon (1984) divide a exposição da metanarrativa ficcional de duas formas. Ao grupo da metaficção implícita considera-se todo o tipo de autorreferência textual internalizado no texto em situações sutis em que o leitor/audiência pode não estar ciente que está diante de uma narrativa metaficcional. Como exemplos dessa modalidade, pode-se citar os gêneros textuais como as histórias de detetive e os trocadilhos em que os textos tem uma relação de estrutura com outros textos ou um sentido diferente do que está escrito. Nestes casos, a história de detetive tem uma estrutura previsível, em que o leitor/espectador reconhece de outras histórias. Assim como nos trocadilhos em que o leitor/espectador, através de um contexto específico, consegue dar sentido à informação recebida.

Já o grupo das modalidades metaficionais explícitas apresenta a autoconsciência de forma bastante evidente e integrada à narrativa. Assim a metaficção explícita pode aparecer por meio de alegoria no enredo, nas metáforas ou até mesmo nos comentários. Hutcheon (1984) salienta que várias técnicas podem ser utilizadas para gerar este efeito, tais como a perspectiva em abismo (mise en abyme $e^{l}$ ) ou até mesmo a criação de um pequeno mundo paralelo com o objetivo de mudar o foco da ficção para a narração. Nesta última possibilidade, o mundo paralelo pode ser criado pelo narrador intradiegético ${ }^{2}$, ao dirigir-se ao leitor/espectador ideal, ignorando a presença dos outros personagens. E, assim, destitui a narrativa principal, ou seja, a narrativa de onde o personagem-narrador parte originalmente, de uma realidade proposta para uma ficção declarada, dando mais credibilidade ao mundo paralelo compartilhado por narrador e narratário. Quando constituído este "mundo paralelo", o leitor não tem mais a impressão, como na ficção realista, de que os acontecimentos se desenvolvem diante dos seus olhos, mas tem a impressão de que participa da ação nem que seja como confidente do personagem, reforçando os laços de relacionamento entre narrador e narratário. 
Genette (1972) alerta que, nestes casos, a narrativa é contada de fora da história. Um autor de um livro está no mesmo nível narrativo de seus leitores, de forma que o autor, pessoa real, é o narrador extradiegético que narra sua história de fora do mundo fictício. E assim, dentro da narração, pode haver outro narrador, este intradiegético, encarregado de narrar uma história que terá alguma relevância para a primeira. E este por sua vez narra para o narratário/ leitor ou espectador ideal.

Segundo Reis e Lopes (1988), o narratário é uma entidade textual que compõe com o narrador uma relação de comunicação semelhante a do autor com o leitor. O narratário é o que Eco (1995) chama de leitor ideal, ou seja, o leitor pra quem o narrador imagina que se dirige, o leitor que o narrador imagina que tenha determinadas informações não contidas na narrativa e que vão beneficiar sua compreensão dela.

Pode-se observar tanto em Genette (1972) quanto em Hutcheon (1984) certa concordância exatamente no ponto em que entendem que a narrativa metaficcional se difere da narrativa tradicional. Na modalidade diegética explícita de Hutcheon (1984) percebe-se a alteração do lugar do leitor ideal/narratário, ao qual o narrador se dirige de forma direta. Ou seja, ao se dirigir de forma direta ao espectador ideal, o narrador rompe com a tradição de ignorar que está sendo "observado" por olhos curiosos. Desta maneira a quarta parede se rompe e a estética da metaficção se consolida. Esta estética, que já foi chamada de antirromance, subverte o que a narrativa realista põe como primordial e desta maneira traz um diferencial para a apreciação estética das obras artísticas.

\section{DERRUBANDO A QUARTA PAREDE}

House of Cards é uma série norte-americana baseada num livro homônimo, do escritor e político britânico Michael Dobbs. A série já havia sido adaptada para a televisão em 1990 pela BBC de Londres, no entanto nesta oportunidade teve apenas uma temporada. Tanto o livro quanto a série britânica contam a história de Francis Urquhart, um político sem escrúpulos que, de forma ilegal, cumpre uma escalada até se tornar o Primeiro Ministro Britânico.

A versão americana da série teve algumas alterações. Em vez de se passar na Inglaterra, se passa nos Estados Unidos. Em decorrência deste fato, o cargo a ser galgado por Francis é o de presidente, já que o país desta versão não possui o mesmo sistema de governo do cenário original, e por consequência, não tem Primeiro Ministro. Outra adaptação foi o sobrenome do protagonista que foi alterado para Underwood, além de ser frequentemente utilizado o apelido de Francis, Frank, para referir-se a ele. 
Nesta versão, após perder a vaga de secretário de estado que esperava no novo governo, Frank resolve tomar o poder por seus próprios meios ilícitos. O personagem possui uma grande rede de colaboradores que estão dispostos a ajudá-lo em seus planos mediante recompensas, às vezes financeiras e às vezes sob a forma de influência. Quando possível se utiliza parceiros eventuais que são captados através de extorsão e chantagem e quando não sevem mais, são descartados.

Para proceder à análise da quebra da quarta parede na série, trazendo a teoria da narrativa para o estudo do audiovosual, selecionou-se 9 trechos relacionados episódios de House of $\operatorname{Cards}^{3}$ (Steindorff :2015), em que se observa a presença de um narrador intradiegético que entrega ao seu espectador ideal uma quantidade maior de informação que ao público interno da série. Desta maneira, o narrador desloca a posição do espectador ideal/narratário para dentro da narrativa, interrompendo com frequência o andamento da história, mesmo diante de outros personagens, para falar com seu espectador ideal e, muitas vezes, dizendo o que pensa sobre o personagem com quem está contracenando.

No campo da metaficção, apoiado principalmente na categoria metaficcional diegética explícita de Hutcheon (1984), são analisadas todas as interações promovidas de parte do narrador para com o leitor, ou no caso o espectador, esperando deste um lugar ativo na construção de sentido da narrativa. Ou seja, ao se deparar com determinada fala do narrador, o espectador/narratário perceberá que este se dirige a ele com exclusividade, rompendo para tanto com a quarta parede.

Em House of Cards, essas interações podem se dar de ter três formas: diegética, confessional e gestual. A categoria diegética trata-se, segundo Steindorff (2015), de antecipações e lembranças de acontecimentos da diegese. Já a categoria confessional trata de emoções, segredos e juízos do narrador que são revelados somente ao espectador/ narratário. A categoria gestual, é aquela em que o narrador intradiegético utiliza apenas expressões faciais e gestos para comunicar alguma coisa ao espectador/narratário.

As três formas distintas de promover a quebra da quarta parede rompem assim com a simulação do "aquário" e da inexistência do público. O narrador passa a construir uma efetiva aproximação com o narratário, buscando o vincular à diegese pela cumplicidade ao antecipar ou lembrar acontecimentos, atribuir valores a outros personagens ou apenas gesticular para o espectador com a certeza de que ele entenderá a mensagem. Desta forma, o narrador cria com o narratário a sensação de cumplicidade capaz, segundo Hutcheon (1984), de exigir, de forma mais enfática, a presença do espectador/narratário diante da obra e criar um mundo paralelo que somente narrador e narratário compartilham. 


\subsection{CATEGORIA METAFICIONAL DIEGÉTICA}

$\mathrm{Na}$ categoria metaficional diegética são agrupadas as interações diegéticas explícitas (HUTCHEON, 1984), nas quais o narrador, para apresentar personagens, antecipa situações e explica os acontecimentos ao espectador, ocorridos no passado diegético, ou seja, em um momento anterior ao início da narrativa. Da mesma forma, esta categoria também pode ser identificada quando o narrador prevê alguma situação que irá ocorrer mais adiante no desenvolvimento da história. Ou ainda explicar a importância de determinado personagem, fazendo o espectador dar mais atenção a ele.

De forma evidente, percebe-se este tipo de ocorrência no primeiro episódio da série em decorrência de o narrador apresentar ao espectador o mundo em que vive. Frank faz um longo discurso sobre o presidente Garret Walker, seu vice, Jim Matthews e a chefe de gabinete do presidente, Linda Vasques, que terão lugares importantes no decorrer da narrativa. Esta cena foi selecionada em função de mostrar, de forma mais explícita e pura, as características da categoria metaficcional diegética. É possível notar que Frank tece poucos comentários a respeito dos demais personagens, dando mais importância às ações que eles desenvolverão na narrativa. (Figura 1).
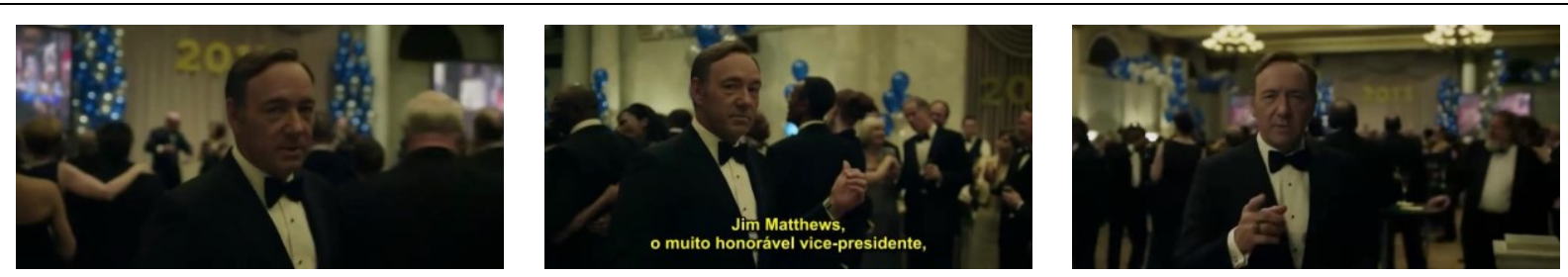

Presidente eleito Garrett Walker. Eu gosto dele? Não. Acredito nele? Pouco importa. Qualquer político que consiga 70 milhões de votos adquiriu acesso a algo maior que ele próprio, até maior que eu, embora odeie admitir. Veja só o sorriso vencedor, os olhos confiáveis. Aliei-me a ele mais cedo e me fiz vital para ele. Após 22 anos no Congresso, sei identificar para que lado o vento sopra. Jim Matthews, o muito honorável vice-presidente, exgovernador da Pensilvânia, cumpriu seu dever conquistando os votos do seu estado - que Deus o abençoe - e, agora, vão fazê-lo se aposentar. Porém, ele parece feliz, não parece? Para alguns só importa o tamanho da cadeira. Linda Vasquez, chefe de gabinete do Walker. Eu a contratei. Ela é mulher, confere. É latina, confere. Porém, o mais importante de tudo: é tão dura quanto carne de segunda. Confere, confere, confere. Quando se trata da Casa Branca, você precisa ter não só as chaves na mão, mas também seu guardião. Quanto a mim, sou o humilde corregedor da Câmara. Mantenho as coisas andando num congresso cheio de mesquinharia e lassidão. Minha função é desentupir os canos e fazer o lodo fluir, mas não terei de ser encanador por muito mais tempo. Cumpri minha pena. Apoiei o homem certo... Assim, posso dizer: Bem-vindos à Washington!

\section{Figura 1: Apresentação da diegese}

Fonte: House of Cards, episódio 1

Nota-se na imagem que Frank se dirige diretamente ao espectador/ narratário ideal. O olhar dele volta-se para a câmera e, consequentemente, para fora da diegese principal (GENETTE, 1972), quebrando a quarta parede. Além disso, percebe-se que ele não está 
preocupado com as pessoas à sua volta, agindo além delas e instituindo assim um nível narrativo outro, distinto do principal. Anda pelo salão ignorando-as e valorizando a conversa com o seu destinatário. Sua fala pode ser interpretada como a apresentação do mundo que o espectador está prestes a inserir-se, e para manter este seu "cúmplice" informado, Frank relata o que aconteceu de relevante até aquele momento.

Ou seja, nota-se um narrador explícito, característico do que Hutcheon (1984) chama de metaficção diegética explícita. E que é colocado como Genette (1972) explicou, em outro nível narrativo que não está no nível dos personagens. Como o autor alerta, o narrador está em um nível diegético imediatamente superior à história que conta. Frank utiliza este nível narrativo superior para dirigir-se ao espectador e fazer comentários sobre a história que está sendo contada na metadiegese.

Através da fala que Frank direciona ao espectador, este pode identificar determinadas informações relevantes da narrativa que ainda serão apresentadas no decorrer da história. Garret Walker é o presidente dos Estados Unidos. Ele fez 70 milhões de votos nas eleições. Jim Matthews é seu vice-presidente, ex-governador da Pensilvânia. Linda Vasques é a chefe de gabinete do presidente. Frank a contratou e é o corregedor da câmara, além de ter se alidado a Walker no início da campanha eleitoral.

Assim o espectador recebe de forma privilegiada informações da história que irá se desenvolver e pode perceber que se desenvolverá, por exemplo, em torno da temática política americana, oportunizando a interação do narrador em momentos chave da narrativa. A categoria metaficcional diegética ainda pode também trazer ao espectador acontecimentos anteriores ao presente da diegese, justificando atitudes do narrador ou seu juízo sobre determinado personagem. Estas informações poderiam ser obtidas no decorrer da série, entretanto, Frank prefere criar um mundo paralelo para ele e seu espectador idealizado, deixado clara a intenção do narrador de criar no narratário/espectador real a impressão de aproximação com a narrativa, ou seja de ser transportado imaginariamente para dentro da diegese na medida em que passar a ser o "único" a compartilhar como ele informações privilegiadas (BALÁZS, 2003).

\subsection{CATEGORIA METAFICCIONAL CONFESSIONAL}

A ocorrência metaficcional encontrada com maior frequência em House of Cards, inclusive em associação com a categoria metaficcional diegética, é a categoria metaficcional confessional. A esta categoria atribui-se as interações referentes a juízos que o narrador faz em relação a outros personagens, confissões a respeito de seus medos e valores, estratégias que está 
desenvolvendo e que não seriam bem vistas se contasse a alguém. Esta categoria agrupa as interações que dizem respeito à personalidade do narrador, sua ética ou falta dela, suas confissões a respeito de coisas bastante privadas de sua vida ficcional.

Percebe-se este tipo de ocorrência, por exemplo, no décimo terceiro episódio de House of Cards, quando Frank está prestes a se tornar vice-presidente dos Estados Unidos, mas ainda enfrenta uma guerra com o empresário Raymond Tusk, conselheiro do presidente. Para diminuir a influência de Tusk junto ao presidente, Frank recorre a SanCorp, uma importante empresa americana que tem como lobista um ex-assessor seu, Remy Danton. (FIG.2)

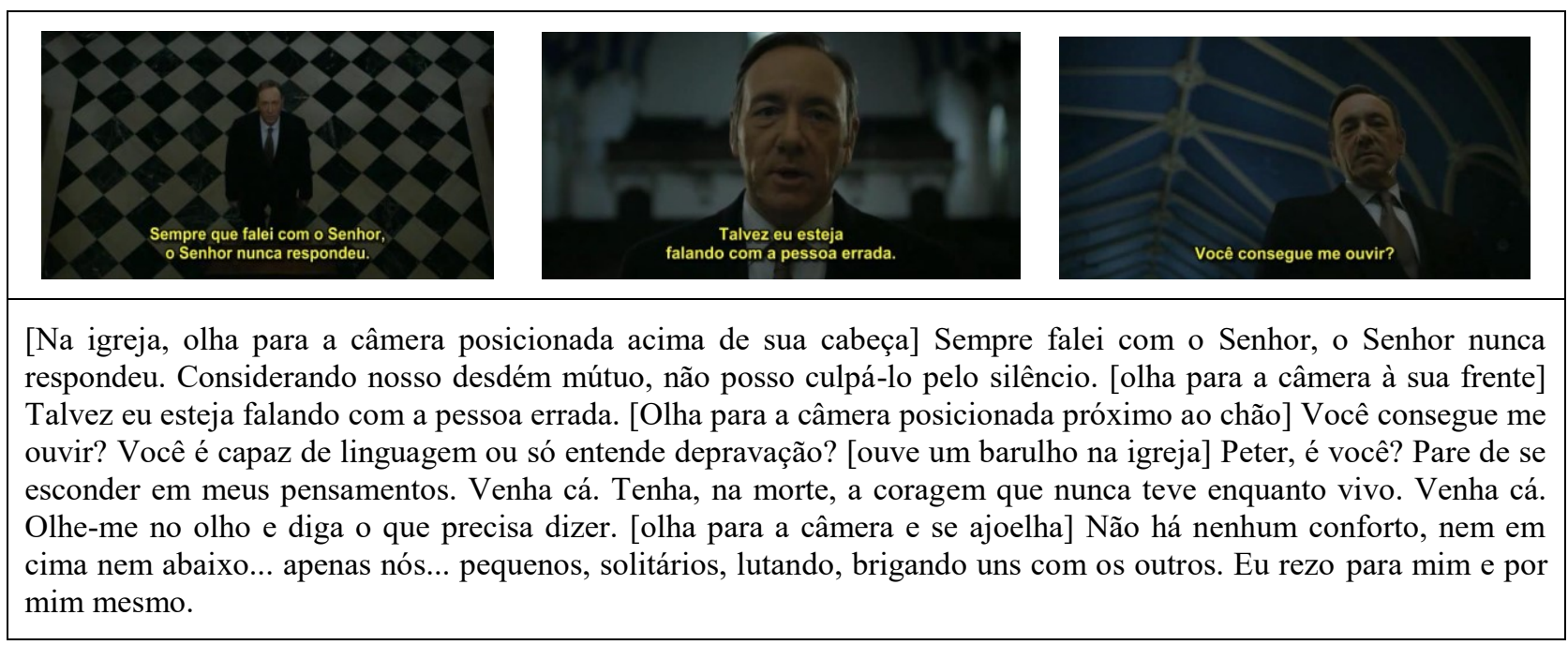

\section{Figura 2: Derrubando os deuses da criação}

Fonte: House of Cards, episódio 13

Deste modo, é como se o narrador na igreja, voltasse-se para o espectador e dissesse que somente ele tem poder sobre a narrativa que conta. A cena também é uma crítica à relação narrador/narratário em metaficções, de forma que ao olhar para cima e dizer Eu sempre falei com o Senhor, o Senhor nunca respondeu Frank solicitasse, como se fosse possível, uma contraparte do espectador.

No segundo momento em que Frank olha para a câmera em sua frente e diz: Talvez eu esteja falando com a pessoa errada, é como se o narrador se colocasse no mesmo nível de poder do espectador/narratário, insinuando que ambos estão da mesma forma à deriva, nas mãos do destino da narrativa. No terceiro momento, em que Frank olha para a câmera próxima ao chão, em posição de superioridade em relação ao espectador, e pergunta: Você consegue me ouvir? Você é capaz de linguagem ou só entende depravação?. Observa-se uma situação dialogal que pode ser interpretada como a de o narrador dizendo que o espectador só pode assistir o desenrolar da história e ouvi-lo, mas é ele, que está dentro da diegese que pode agir e falar. 


\subsection{CATEGORIA METAFICCIONAL GESTUAL}

$\mathrm{Na}$ terceira categoria, a metaficcional gestual, observam-se as interações em que o narrador não utiliza a fala para fazer um endereçamento ao espectador/narratário, mas gestos e performances. Assim pode dirigir-se ao narratário através de olhares, gestos com a cabeça ou com as mãos em situações, geralmente, em que já explicou o que aconteceria através da adoção das categorias anteriores.

Ou seja, a categoria metaficcional gestual, na maioria das vezes, é antecedida por uma interação do tipo metaficcional diegética, por se tratar de uma confirmação de uma situação prevista, bem como, da mesma forma, há situações que também se sucedem após a interação do tipo metaficcional confessional.

Devido a estas características que reforçam a comunicação não verbal, é possível conceder à categoria metaficcional gestual a maior importância no rompimento da quarta parede (XAVIER, 2003) nesta série por não se utilizar de recursos sonoros e eventuais verbais, já que só seria possível com o olhar do narrador diretamente para a câmera. Por esta razão, até mesmo as demais categorias se reconfiguram, indicando a mudança de nível diegético (GENETTE, 1972).

Em House of Cards a utilização da expressão gestual, muitas vezes substitui diálogos que servem para reforçar ideias já expostas. Os diálogos verbais, nesses casos, além de desnecessários soam como artificiais na narrativa. Os recursos gestuais e faciais mostram-se mais sutis e sofisticados que os verbais. Ao mesmo tempo, a utilização desse tipo de interação reforça a cumplicidade do narrador com o espectador/narratário, colocando essas duas entidades tão próximas que são capazes de se comunicarem apenas através de um olhar em determinadas situações. Novamente, reforça-se e altera-se a relação entre o narrador e o narratário/espectador na medida em que o primeiro exige maior participação do segundo (HUTCHEON, 1984). (FIG.3).

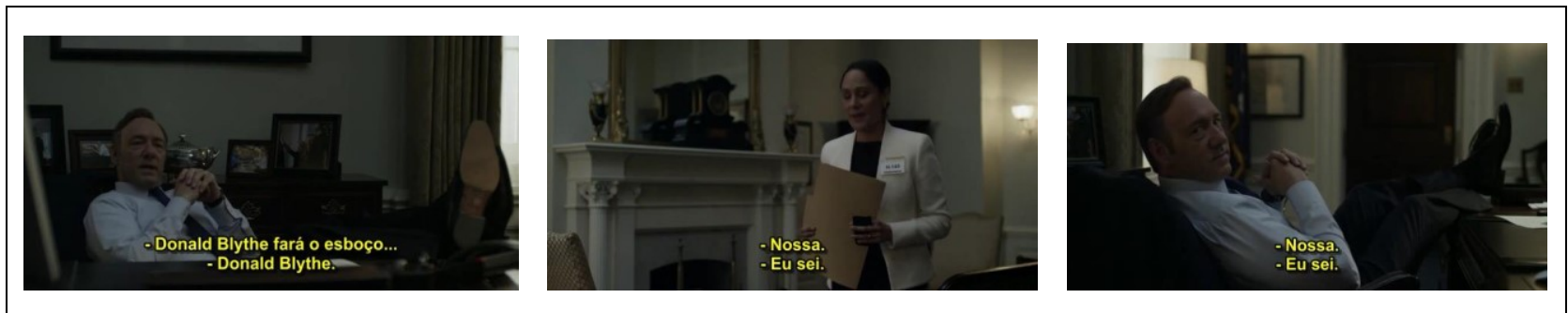

Frank olha pra câmera durante uma reunião com Linda Vasquez, reafirmando as informações que passou ao espectador sobre a reforma educacional

Figura 3: Gestual

Fonte: House of Cards, episódio 1 
Percebe-se que a interação metaficcional confessional, que antecede a interação metaficcional gestual, tem importância fundamental para a compreensão do gesto utilizado. Esse novo lugar distintivo concedido ao narratário também exige, por outro lado, sua maior participação interpretativa (HUTCHEON, 1984), por meio da qual se estabelecem identificações (BALÁZS, 2003) com a posição de segunda pessoa do relato, e não com um personagem específico.

\section{CONSIDERAÇÕES FINAIS}

Ao contrário do aprisionamento da ficção (XAVIER, 2003) proposto pela quarta parede desde os tempos do teatro, na metaficção dos tipos diegética, confessional e gestual a narrativa projeta-se para fora da tela, rompendo as paredes que a continham. Fazendo, desta maneira, com que o espectador/narratário acorde da impressão onírica de realidade (BERNARDET, 2001) e participe, mesmo que imaginariamente da construção de um novo microcosmo pautado pela aproximação com o narrador.

House of Cards, portanto, só pode ser concebido quando se rejeita a proposição de Metz (1985) de que a ilusão de realidade proposta pelo audiovisual só se mantém quando se escondem as marcas da enunciação fílmica. Assim, a análise permite observar que as categorias metaficcionais evidenciam a metaficção, denotando motivações para a quebra da quarta parede de forma que o narratário/espectador é estimulado a estabelecer mais proximidade e vinculação com o narrador.

Ou seja, é oferecida ao espectador a possibilidade de ser o destinatário idealizado pelo narrador e assim poder se identificar, com a posição de segunda pessoa do relato. A pessoa a qual a narração é dirigida, o destinatário específico do relato, desfruta assim de uma relação de cumplicidade junto ao narrador, desfrutando de informações e confidências privilegiadas.

Em razão disso, a problematização proposta traz possíbilidades de novas abordagens ao estudo da metaficção, bem como dos recursos estéticos utilizados em novos produtos audiovisuais, complexificando esta relação. E oportunizando a reflexão sobre a adoção de recursos não exatamento novos ou originais, mas que apresentam na perspectiva do audiovisual novas abordagens e atualizações.

\section{NOTAS}

1 Para Prince (1989) o a expressão mise em abyme significa uma duplicação da obra dentro da própria obra. Segundo o autor este termo tem origem na heráldica, ciência que estuda os brasões. Diz-se que a figura no brasão está em abyme, quando ela representa uma duplicação do brasão em miniatura, no próprio brasão. No caso do audiovisual seria como utilizar uma câmera apontada para um televisor. Se 
o sinal da câmera fosse colocado no mesmo televisor que está sendo utilizado de modelo, seria possível perceber vários televisores, um representado dentro do outro.

2 Segundo Genette (1972), o narrador intradiegético é aquele que é percebido dentro do mundo fícctício, mundo também chamado de diegese. Este narrador é subordinado ao narrador extradiegético, mas também pode ter outro narrador intradiegético, subordinado a ele, em outra metadiegese.

3 A metodologia de análise apresentada neste artigo está embasada na dissertação de mestrado apresentada ao Programa de Pós-Graduação em Letras - UNISC, sob o título Além de um castelo de cartas - a metaficção na série House of Cards. O estudo buscou mostrar a estética metaficcional utilizada quando o narrador/personagem dirigia-se diretamente ao espectador. Disponível em http://btd.unisc.br/Dissertacoes/GabrielSteindorff.pdf.

\section{REFERÊNCIAS}

BALÁZS, Béla. O homem invisível. In.: XAVIER, Ismail (Org.). A experiência do cinema: antologia. 3. ed., rev. e aum. Rio de Janeiro: Graal, 2003.

Nós estamos no filme. In.: XAVIER, Ismail (Org.). A experiência do cinema: antologia. 3. ed., rev. e aum. Rio de Janeiro: Graal, 2003.

BERNARDET, Jean-Claude. O que é cinema. São Paulo: Brasiliense, 2001.

BROWNE, Nick. O espectador-no-texto: a retórica de "No tempo das diligências". In.: RAMOS, Fernão (Org.). Teoria contemporânea do cinema. São Paulo: SENAC-SP, 2005. Volume II.

GENETTE, Gérard. Figuras III. Barcelona: Lumen, 1972.

HUTCHEON, Linda. Narcissistic narrative the metafictional paradox. Waterloo: Wilfrid Laurier University Press, 1984.

METZ, Christian. História-discurso. In.: GEADA, Eduardo (Org.). Estéticas do Cinema. Lisboa: Dom Quixote, 1985.

PRINCE, Gerald. Dictionary of narratology. Lincoln: University of Nebraska Press, 2003.

REIS, Carlos; LOPES, Ana Cristina M. Dicionário de teoria da narrativa. São Paulo: Ática, 1988. 327 p.

STEINDORFF, Gabriel. Além de um castelo de cartas: a metaficção na série House of cards. 2015. 104 f. Dissertação (Mestrado) - Universidade de Santa Cruz do Sul, 2015. Disponível em http://btd.unisc.br/Dissertacoes/GabrielSteindorff.pdf

XAVIER, Ismail. O olhar e a cena: Melodrama, Hollywood, Cinema Novo, Nelson Rodrigues. São Paulo: Cosac \& Naify, 2003. 